\title{
Understanding the Space of Research
}

\author{
Dhritikesh C* \\ Department of Statistics, Handique Girls' College, India
}

Submission: October 20, 2017; Published: January 22, 2018

*Corresponding author: Dhritikesh Chakrabarty, Department of Statistics, Handique Girls' College, India

Email: dhritikesh.c@rediffmail.com,dhritikeshchakrabarty@gmail.com

Abstract

The theory of research, the history of the beginning of whose development was lost in the dust of antiquity, has been found to be the vital player in playing the role of developing knowledge everywhere. At the current stage of human civilization, research has become an unavoidable and essential component of each and every branch/field of academic world. The research is not only an unavoidable component of academic activity but also a partner/helper for most of the problems in the society. A journey has been made for understanding the space of research specifically on the meaning of research, definition of research, characteristics of research, methodology of research, types of research etc. This paper is based on some of the findings obtained in the study.

Keywords: Research; Research process; Characteristics; Methodology; Types

\section{Meaning and Definition of Research}

o $\quad$ Research is a detailed study of a subject, especially in order to discover (new) information or reach a (new) understanding.

o The word "research" is used to describe a number of similar and often overlapping activities involving a search for information. For example, each of the following activities involves such a search; but the differences are significant and worth examining.

o Research means searching for the facts, searching for the replies to the various queries and also for the solutions to the various problems.

o Research is an inquiry or an investigation with a specific purpose to fulfill, it helps in clearing the various doubtful concepts and tries to solve or explain the various unexplained procedures or phenomena.

o According to the encyclopedia of social science, research can be explained as 'the manipulation of generalizing to extend, connect or verify knowledge.'

o Research is the investigation of a particular topic using a variety of reliable, scholarly resources.

o The three major goals of research are establishing facts, analyzing information, and reaching new conclusions. The three main acts of doing research are searching for, reviewing, and evaluating information.

o A scientific investigation of phenomena which includes the collection, presentation, analysis and interpretation of facts that link man's speculation with reality [1-4].

\section{Dictionary definitions}

o To search or investigate exhaustively.

o Studious inquiry or examination; especially: investigation or experimentation aimed at the discovery and interpretation of facts, revision of accepted theories or laws in the light of new facts, or practical application of such new or revised theories or laws.

o The collecting of information about a particular subject [5-8].

\section{A librarian's definition}

o Research is a process of investigation, an examination of a subject from different points of view. It's not just a trip to the library to pick up a stack of materials, or picking the first five hits from a computer search. Research is a hunt for the truth. It is getting to know a subject by reading up on it, reflecting, playing with the ideas, choosing the areas that interest you and following up on them. Research is the way you educate yourself.

o Research is defined as the creation of new knowledge and/or the use of existing knowledge in a new and creative way so as to generate new concepts, methodologies and understandings. This could include synthesis and analysis of previous research to the extent that it leads to new and creative outcomes.

Note

i. This definition of research is consistent with a broad notion of research and experimental development (R \& D) 
as comprising of creative work undertaken on a systematic basis in order to increase the stock of knowledge, including knowledge of humanity, culture and society, and the use of this stock of knowledge to devise new applications.

ii. This definition of research encompasses pure and strategic basic research, applied research and experimental development. Applied research is original investigation undertaken to acquire new knowledge but directed towards a specific, practical aim or objective (including a clientdriven purpose) [9].

\section{What research isn't?}

o Research isn't teaching.

o Research isn't encyclopedic.

o Research isn't just data-gathering.

o Research isn't just about methodology.

o Research isn't repetition, except in some special circumstances.

\section{Research process}

o The research process is the methodical approach to finding and examining a variety of reliable, scholarly resources on a particular topic.

o The research process has a beginning and an end, with many stages or steps in between. Each one of these steps is built upon the foundation of information. Brainstorming ideas, searching for resources, and analyzing ideas are all information-based activities.

The Research Process in Six Steps:

Step 1: Determining Research Needs

Step 2: Defining a Research Topic

Step 3: Developing a Search Strategy

Step 4: Conducting the Search

Step 5: Evaluating Resources

Step 6: Citing Resources

\section{Components of the research process}
I. Problem/Objectives
II. Hypotheses
III. Theoretical/Conceptual Framework
IV. Assumptions
V. Review of Related Literature
VI. Research Design
VII. Data Collection

VIII. Data Processing and Statistical Treatment
IX. Analysis and Interpretation
X. Summary, Conclusions and Recommendations

\section{Features of good research procedure}
a. Should be systematic in nature
b. Should be logical
c. Should be empirical and replicable in nature
d. Should be according to plans
e. Should be according to the rules and the assumptions should not be based on the false bases or judgments
f. Should be relevant to what is required
g. Procedure should be reproducible in nature
h. Controlled movement of the research procedure

\section{Characteristics of research}

I. Research is based on the scientific method

II. Helps in answering various pertinent questions

III. It is an organized, planned and patient investigation or a critical enquiry

IV. It has logical roots, helping to establish facts or principles

V. Analytical \& critical i.e. going deeper into the depth of the idea

VI. Systematic i.e. employing valid procedure and principle

VII. Controlled i.e. keeping the variable constant

VIII. Accurate i.e. conducting a careful investigation

IX. Replicability: The research design and procedures are replicated to enable the researcher to arrive at valid conclusive results

X. Cyclical: Research is a cyclical process. It starts with a problem and ends with a problem

XI. Empirical: Research is based on direct experiences or observation alone by the researcher

XII. Requires courage: calling the researchers will to continue the work in spite of the problem

XIII. Original work: producing a work of your own by making use of scientific process

XIV. Patient and unhurried activity: requiring an effort making a capacity

XV. Hypothetical: giving an intelligent guess before presenting the conclusion 
XVI. Done by an expert: making the research more reliable and tested

XVII. Critical: Research exhibits careful and precise judgment. A higher level of confidence must be established. For example, 1 or 5 percent level of confidence, and based on these levels of confidence, the researcher is precise on his interpretation whether to have significant or insignificant results

XVIII. Logical. Research is based on valid procedures and principles. Methodical Research is conducted in a methodical manner without bias using systematic method and procedures

\section{Types of Research}

\section{Classification}

First way of classification: In the first thinking, researches can be classified into two broad types namely
A. Theoretical type of researches
B. Applied type of researches

Theoretical researches can again be classified into three subclasses namely

I. Conceptual type of researches

II. Theory development type of researches

III. Methodological type of researches

Similarly, applied types of researches can be classified into two subclasses namely

o Art of application (methodological in other words) type of researches

o Application in real situation (reality) type of researches

Second way of classification: $0 n$ the basis of the experimentation involved, researches can be classified into two broad types namely
A. Experimental type of researches
B. Non-experimental type of researches.

Experimental type of researches can be classified into two subclasses. They are

I. theory-development type of researches

II. Applied type of researches.

Similarly, non-experimental type of researches can also be classified into two subclasses which are

I. theory-development type of researches

II. Applied type of researches respectively.
Third way of classification: On the basis of the dependence of one research upon another, researches can be classified into four broad types namely
a. Original type of researches,
b. Extension type of researches,
c. Modification type of researches
d. Application of existing theory type of researches.

Fourth way of classification: On the basis of the ways and purposes of study, researchers can be classified into four broad types namely
Survey research
o Public opinion polls
o Mail Surveys
o Telephone Surveys
o Consumer Surveys (in the Mall)

\section{Focus type of research}

A focus group gathers in-depth information by interviewing six to twelve experts in an informal discussion that lasts one to two hours. An experienced interviewer gathers opinions of the group.

\section{Case studies}

A case study looks at existing information that is readily available and attempts to draw conclusions from this information.

\section{Delphi type of research}

The Delphi method surveys the opinions of "expert panels". The research is conducted in three rounds, where the information is gathered, refined and then feed back to the expert participants. The feedback stage allows issues to be sharpened and helps to highlight the major issues involved [10-12].

\section{Content analysis}

Content analysis is often used in quantitative research to study trends or occurrences of information.

\section{Other Types:}

Basic research: This is also called as "fundamental research" or "pure research". It seeks to discover basic truths or principles.

Applied research: This type of research involves seeking new applications of scientific knowledge to the solution of a problem, such as a development of a new system or procedure, new device, or new method in order to solve the problem.

Developmental research: This is a decision-oriented research involving the application of the steps of the scientific method in response to an immediate need to improve existing practices. 
Library research: This is done in the library where answers to specific questions or problems of the study are available.

Field research: Here, research is conducted in a natural setting.

Laboratory research: The research is conducted in artificial or controlled conditions by isolating the study in a thoroughly specified and equipped area.

The purposes are:

o To test hypotheses derived from theory,

o To control variance under research conditions, and

o To discover the relations between the dependent and the independent.

\section{Research methods}

Observational method: With the observational method (sometimes referred to as field observation) animal and human behavior is closely observed. There are two main categories of the observational method - naturalistic observation and laboratory observation.

Case study method: Case study research involves an in-depth study of an individual or group of individuals.

Survey method: In survey method research, participants answer questions administered through interviews or questionnaires. After participants answer the questions, researchers describe the responses given.

Experiments: People who take part in research involving experiments might be asked to complete various tests to measure their cognitive abilities (e.g. word recall, attention, concentration, reasoning ability etc.) usually verbally, on paper or by computer. The results of different groups are then compared. ple should not be put off by this either.

Surveys: Surveys involve collecting information, usually from fairly large groups of people, by means of questionnaires but other techniques such as interviews or telephoning may also be used.

Case studies: Case studies usually involve the detailed study of a particular case (a person or small group).

Participant and non-participant observation: Studies which involve observing people can be divided into two main categories, namely participant observation and non-participant observation. In participant observation studies, the researcher becomes (or is already) part of the group to be observed. In nonparticipant observation studies, the researcher is not part of the group being studied.

Observational trials: Observational trials study health issues in large groups of people but in natural settings.

Studies using the delphi method: The Delphi method was developed in the United States in the 1950s and 1960s in the military domain. It has been considered particularly useful in helping researchers determine the range of opinions which exist on a particular subject, in investigating issues of policy or clinical relevance and in trying to come to a consensus on controversial issues [13-15].

\section{Types of research based on research method}

Typology of research: Research can be classified in many different ways on the basis of the methodology of research. The knowledge it creates, the user group, the research problem it investigates etc.

Basic research: The research which is done for knowledge enhancement, the research which does not have immediate commercial potential. The research which is done for human welfare, animal welfare and plant kingdom welfare. It is called basic, pure, fundamental research.

Applied research: Applied research is designed to solve practical problem of the modern world, rather than to acquire knowledge for knowledge sake.

Quantitative research: Quantitative research aims to measure the quantity or amount and compares it with past records and tries to project for future period.

Qualitative research: Qualitative research presents nonqualitative type of analysis. Qualitative research is collecting, analyzing and interpreting data by observing what people do and say. Qualitative research refers to the meanings, definitions, characteristics, symbols, metaphors, and description of things.

Mixed research: Mixed research combines qualitative and quantitative research into one single study. In this sense both qualitative and quantitative research methods, techniques, and characteristics are combined into one overall study.

Action research: Action research is a research model that follows accomplishment and studying at the same time.

Detailed action research: The general approach to action research is for the researcher to first identify the problem and collect data on the related problem so that a more detailed diagnosis can be identified.

Detailed mixed research: The general approach to mixed research is for the researcher to use the qualitative research model for one phase of the research project and the quantitative research model for another phase of the research project.

\section{Research and Statistics}

\section{Definition of statistics}

Statistics has been defined differently by different authors. There are two ways of defining namely

A. Definition as statistical data

B. Definition as statistical method 


\section{A. Definitions of statistics as statistical data: Statistics} have been described, as statistical data, by the following definitions.

i. Webster's definition: According to Webster," Statistics are the Classified facts representing the conditions of the people in a state, especially those facts which can be stated in numbers or any tabular or classified arrangement."

ii. Definition due to yule and kendall: According to Yule and Kendall, "Statistics means quantitative data affected to a marked extent by multiplicity of causes."

iii. Bowley's definition: Professor Bowley defined statistics (as statistical data) in the following manner: "Statistics are Numerical Statements of facts in any department of enquiry placed in relation to each other.

iv. Definition by Prof. Horace Secrist: More broad definition of statistics was given by Prof. Horace Secrist. According to him, "Statistics means aggregates of facts affected to a marked extent by multiplicity of causes, numerically expressed, enumerated or estimated according to reasonable standards of accuracy, collected in a systematic manner for a predetermined purpose and placed in relation to each other". This definition points out some essential characteristics mentioned below:

I. They are enumerated or estimated according to a reasonable standard or accuracy.

II. They are affected by multiplicity of factors.

III. They must be numerically expressed.

IV. They must be aggregate of facts. Numerical facts may be called statistics if and only if they possess these characteristics.

B. Definitions of statistics as statistical method: Statistics have been described, as statistical method, by the following definitions.

I. Bowley's definition: Professor Bowley, who had defined statistics (as statistical data) earlier, defined statistics later (as statistical method) in the following manner:Statistics can be defined to be the

o Science of Counting,

o $\quad$ Science of Averages

o Science of Measurement of Social Organism.

II. Boddington's definition: According to Boddington, Statistics is the Science of Estimates and Probabilities.

III. King's definition: According to King, "The science of statistics is the method of judging collective, natural or social phenomena.

IV. Lovitt's definition: According to Lovitt, "Statistics is the science which deals with collection, classification, description and comparison of phenomena.

V. Definition by croxton and cowden: Croxton and Cowden defined statistics (as statistical method) in the following manner. "Statistics is the science which deals with the collection, analysis and interpretation of numerical data". This definition is the universally accepted definition of statistics at the current stage of the development of statistical science $[16,17]$.

\section{Jobs in Statistics}

The works/jobs to be done in statistical science can be classified into the following stages:

o Collection of Data: In this stage, data/information/ observations required under study are collected.

o Scrutiny of Data: Data/information/observations collected, in stage 1 , are verified/scrutinized in this stage

o Classification of Data: Verified/scrutinized data are classified according to requirement/convenience are classified/tabulated In this stage.

o Analysis of Data: In this sate, classified/tabulated data are analyzed.

o Interpretation of Results: Results/outcomes/findings obtained in the earlier stage, are interpreted In this stage.

o Drawing of Conclusion/Inference: Based on the results/outcomes/findings and interpretations obtained in the earlier two stages, conclusions/inferences are drawn in this stage.

Note: Observing the six stages, one can interpret that jobs to be done in statistical science can be broadly treated as three-stage jobs namely Collection Stage, Classification Stage (comprising Scrutiny of Data of \& Classification of Data) and Analysis Stage (comprising of Interpretation of Results \& Drawing of Conclusion).

\section{Jobs in Research}

The works to be done in scientific investigation and research, in general, can be classified in the following steps arranged in chronological sequence:

Association to problem: In the first step, researcher/ investigator requires to be associated with the problem existing in the field of interest.

Detection of problem (for imposed research)/ fixing of problem (for own research, thrust, adventure etc.): In the next step, researcher/investigator requires to detect the problem(s) existing in the field of interest which need(s) research/investigation.

Fixing/setting of objective: In this step, researcher/ investigator requires to fix problem(s) and to set the objective(s) for study. 
Setting up of hypothesis if any: Here, the hypothesis to be tested is to be framed of. Normally, a null hypothesis is framed of against an alternative hypothesis with a level of significance (and also with power of the test if necessary).

Perform experimentation (for Experimental Research)/search for logic/derivation method (for theoretical research): In this step, experimentation is performed or survey is conducted depending upon the requirement if the research is of experimental type. For theoretical research, logic for (or method of derivation of development of theory is searched for in this step.

Collection of information/observation/data: In this step, data/observation/information is collected for experimental research.

Scrutiny of data: The jobs in this step consist of

o Detection of Necessary Data \& Unnecessary Data etc.,

o Remove Unnecessary/Irrelevant Data,

o Verification of Error(s) in Data,

o $\quad$ Correct Error(s) from Data (having Error) if Possible,

o Remove Data having Error(s) if Not Possible to Correct,

o Detect Qualified Observation/Data (for Analysis),

o Detect Unqualified Observation /Data (Not to be Used in Analysis).

Classification of data: Classification of data/observation/ information, representation of data/observation/information, Tabulation of data/observation/information, Conversion of form of data/observation/information from the form in collection to the required form is to be done in this step.

Analysis of data: Analysis of data/observation/information is to be done in this step. The two broad aspects of analysis are determination (estimation in statistical terminology) and testing of hypothesis.

Interpretation of results: Results/outcomes/findings obtained in the earlier stage, are interpreted in this stage.

Drawing of conclusion: Based on the results/outcomes/ findings and interpretations obtained in the earlier two stages, conclusions/inferences are drawn in this stage.

Note: The works to be done in scientific investigation and research and the jobs to be done in statistics are similar. Thus, statistics is fully associated to scientific investigation and research. Also, in any investigation and/or research work, Scrutiny of Data, Classification of Data, Analysis of Data, Interpretation of Results/Findings \& Drawing of Conclusion/ Inference, Prescription, Recommendation etc, cannot be performed without the help of statistical method (s). That is why statistics can be regarded as essential and unavoidable component of scientific investigation and research.

\section{Some Comments}

\section{Value of research to man}

o Research improves the quality of life.

o Research improves instruction.

o Research improves students' achievement.

o Research improves teacher's competence.

o Research satisfies man's needs.

o Research reduces the burden of work.

o Research has deep-seated psychological aspects.

o Research improves the exportation of food products.

o Research responds to the economic recovery and austerity measure of the country.

o Research trains graduates to become responsive to the economic development of the country and to compete globally $[18,19]$.

\section{Limitations of research}

o Problems of collection of data and conceptualization may occur.

o Repetition problems.

o Outdated and insufficient information system may cause problems.

o Sometimes lack of resources becomes an obstacle.

o Non-availability of trained researchers.

o Absence of code of conduct.

\section{Conclusion}

Qualitative research aims to gather a more inclusive understanding as to a particular behavior and the reasons as to why such behavior exists. Quantitative research aims to determine the relationship between one thing and another. Mixed research comes into play when the aim is to use a mixture of research methods to come to a comprehensive conclusion on the subject at hand. Action research is used when a problem exists with a process and improvements need continually be made to advance the process. The researcher will need to investigate the topic at hand in order to come to a conclusion on which of these research methods to use. Statistics is analytical tool for scientific investigation and research. Statistics is essential and unavoidable tool for scientific investigation and research. Statistics exists everywhere, everyday and with everybody. Everybody uses statistics everyday knowingly or unknowingly. Statistics is great significance carrying wide application in reality (Figure 1) [20,21]. Its significance was summarized by Florence Nightingale as follows: 


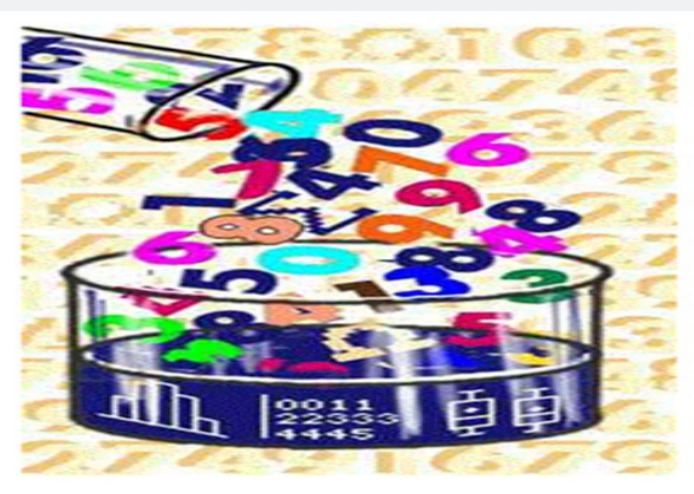

Figure 1: Statistics the most important science in the whole world.

\section{Statistics}

The most important science in the whole world: for upon it depends the practical application of every other science and every art: the one science essential to all political and social administration, all education, all organization based on experience, for it only gives results of our experience. Florence Nightingale.

\section{References}

1. Bayes T (1958) Thomas Bays essay towards solving a problem in the doctrine of chances (Studies in the history of probability and statistics). Reproduced from Philos. Trans Roy Soc London Ser A53 45: 293-315.

2. Bernoulli J (1713) Arts Conjectandi. Impensis Thurnisiorum Fratrum Basileae.

3. Iverson MG, Gergen M (1997) Statistics: The Conceptual Approach. Springer-Verlag, New York, USA.

4. Geiringer H (1957) Probability, Statistics and Truth. Allen G \& Unwin Ltd, London, UK.

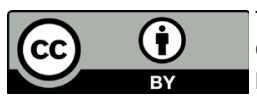

This work is licensed under Creative Commons Attribution 4.0 Licens DOI: 10.19080/BBOAJ.2018.04.555642
5. Geiringer H (1964) Mathematical Theory of Probability and Statistics. Academic Press, New York.

6. Lappan G, Frey JT, Fizgerald WM, Friel SN, Phillips ED (1998) Teacher's Guide Connected Mathematics: Samples and Populations. Menlo Park, CA: Dale Seymour Publications, USA.

7. Landwehr JM, Watkins AE (1995) Exploring Data. Palo Alto, CA: Dale Seymour Publications, USA.

8. Maistrov LE (1974) Probability Theory A Historical sketch. Academic Press, New York, USA p. 1-10.

9. Rubenstein RN, Craine TV, Butts TR (1995) Teacher's Edition Integrated Mathematics. Houghton Mifflin Inc., Boston, USA.

10. Savage LJ (1954) The Foundations of Statistics. John Wiley, New York, USA.

11. Mises RV (1930) Veroyatnost' i statistika, In: Moscow-Leningard, Probability and Statistics, Academic Press, New York, USA.

12. Mises RV (1931) Wahrscheinlichkeits Rechnung. In: Geiringer, English Edition.

13. von Mises R (1938) Ueber Aufteilungsund Besetzungs Wahrscheinlichkeiten. Revve de la Faculte des Sciences de l' Universite d' Istanbul 4: 145-163.

14. von Mises R (1939) Probability, Statistics and Truth. MacMillan.

15. Commonwealth of Learning, British Columbia, Canada.

16. Quantitative and Qualitative Research (2011) Types of research designs.

17. O'Brien R (1998) An overview of the methodological approach of action research.

18. Rohrer C (2008) When to use which user experience research methods. Nielsen Norman Group.

19. Stangor C (2007) Research Methods for the Behavioral Sciences ( $3^{\text {rd }}$ edn). MA: Houghton Mifflin Company, Boston, USA.

20. Weathington BL, Cunningham CJL, Pittenger DP (2010) Research Methods for the Behavioral and Social Sciences. Hoboken, NJ: John Wiley \& Sons, Inc.

21. Jackson SL (2009) Research Methods and Statistics: A Critical Thinking Approach $\left(3^{\text {rd }}\right.$ edn). Belmont, CA: Wadsworth.

\section{Your next submission with Juniper Publishers}

will reach you the below assets

- Quality Editorial service

- Swift Peer Review

- Reprints availability

- E-prints Service

- Manuscript Podcast for convenient understanding

- Global attainment for your research

- Manuscript accessibility in different formats

( Pdf, E-pub, Full Text, Audio)

- Unceasing customer service

Track the below URL for one-step submission https://juniperpublishers.com/online-submission.php 